\title{
Geophysical Characterization of Subsurface Layers and Soil Competency of Naraguta Campus, University of Jos-Nigeria
}

\author{
Janet Agati-Yakubu Sunday Sani Daku Lohfa Wuyep Nimze ${ }^{*} \quad$ Winifred Naanlep Dajilak \\ Yaba Daniel Douglas Vincent Santos Anyip \\ Department of Geology, Faculty of Natural Sciences, University of Jos, PMB 2084, Jos-Nigeria
}

\begin{abstract}
The utilization of geophysical methods can increase the effectiveness of civil engineering works since it can provide the information which the conventional civil engineering method was hard to determine due to the concern of money, time and quality. One of such geophysical methods is the Electrical resistivity using the Schlumberger array which was employed in this study. The study identified three lithological units of top lateritic soil, weathered / fractured basement and the fresh basement. The thickness of the top lateritic soil ranges from $0-4 \mathrm{~m}$, the weathered/ fractured basement has an average thickness in the range of $3.0-25 \mathrm{~m}$ while the fresh basement thickness ranges from $25 \mathrm{~m}$ to infinity. The resistivity values of the sub-surface layers range from $11.40 \Omega \mathrm{m}$ to $5896.7 \Omega \mathrm{m}$ with most of the lithological units rated competent to highly competent. This study serves as basis for further engineering investigation for the design and construction of proposed buildings and has shown the relevancy of the application of geophysics to civil engineering works.
\end{abstract}

Keywords: Competence, Resistivity, Schlumberger, Sub-surface layers, VES

DOI: $10.7176 / \mathrm{JEES} / 11-10-03$

Publication date:October $31^{\text {st }} 2021$

\section{Introduction}

Construction engineering involves the designing, planning, construction, and management of physical infrastructure, which may include roads, bridges, buildings, dams and utilities. All of these types of facilities have a physical footprint that requires some type of modification of the ground, which may involve the insertion of anchors, ground compaction or excavation.

Most construction engineering projects generally require information on subsurface ground conditions to maximum depths of only $50 \mathrm{~m}$ or so below the ground surface. This zone can encompass soil, groundwater, unconsolidated sediments, weathered rock, and competent bedrock. It can also contain products of our own invention, including utilities, buried waste, and contaminants. Typical parameters of interest to designers and engineers are the thickness and extent of layers, the physical properties of layers and any variability within them, and any structure within the ground (Alastair et al., 2016). These can be deciphered using geophysical means as the methods are cost-effective and non- invasive. Some of the geophysical methods which are commonly used in civil engineering to characterize the sub- surface are Electrical resistivity, Seismic, Ground Penetrating Radar, Electromagnetic and Gravity surveys. Geophysical techniques also can be of help in locating cavities, backfilled mineshafts and dissolution features in carbonate rocks and can be extremely useful in determining the stiffness properties of the ground (Clayton, 1996). However, since such potentials of geophysics in engineering are yet to be realized, the application of these techniques are still not being fully utilized (Moh'd et al., 2011).

According to Clayton (1996), geophysical techniques offer the chances to overcome some problems inherent in more conventional geotechnical ground investigation which involves drilling, trenching and trial pitting, from which representative disturbed and/or undisturbed samples of the $i n$-situ materials may be obtained and analysed and Standard Penetration Test and others which can be correlated with other engineering data. Soupios et al. (2007) posited that data obtained through indirect geophysical techniques would contribute to the decision making process for choosing the appropriate footing of a structure based on the subsurface inhomogeneity of the site. The electrical resistivity method in particular, has been employed in studies such as depth to bedrock determination, mapping of superficial deposits, structural mapping, aquifer delineation, saline water mapping, lithological differentiation, and the determination of structural trends etc. In this survey, the conventional resistivity method of Vertical Electrical Sounding (VES) was employed. The VES method was chosen for this study because it has been proven to be a more economical, quick and effective exploration tool for groundwater and engineering geological investigations.

The electrical resistivity survey was embarked upon based on its capability to delineate geological structures such as fractures, faults as well as vertical or near vertical contacts. The delineation of such features is of prime importance in engineering geological site investigation and hydrogeological mapping. This is because any of the features mentioned above can be zones of weakness through which impounded water is lost along dam axis or within reservoir floor. Foundation failure arising from differential movement in the event of tectonic activity along linear features or structures can result in the collapse of civil engineering structures such as dams, buildings and roads. So it is important to investigate these structures to avoid consequent disaster. 
The study area falls in the basement terrain underlain by the Precambrian crystalline rocks $(600 \pm 150 \mathrm{Ma})$ typical of the Nigeria Basement Complex located on the Naraguta Sheet $168 \mathrm{SW}$. These rocks exhibit structures like joints, veins, faults and dykes. The rock types found in the study area include; the Jos biotite granite, Aplopegmatitic granite gneiss, the Neil's valley granite porphyry, and Naraguta quartz-pyroxene-fayalite porphyry with the dominant rock type being the Aplo-pegmatitic granite gneiss (MacLeod, 1971).

This research study was necessitated by the recent massive infrastructural development works being carried out within the Naraguta Campus of the University of Jos, which falls majorly within area of study. The work will complement directly or indirectly the geotechnical Standard Penetration Test drilling which may not be cost effective.

\section{Method of Study}

Electrical resistivity method of geophysical prospecting was employed using the Schlumberger electrode configuration with the aid of Omega SAS 3000 Resistivity Meter. This method measures the conductivity of the subsurface materials by passing electric current through the ground. Twenty-four (24) VES points covering four (4) profiles A- $\mathbf{A}^{\prime}$ and B-B', C-C' and D-D' respectively (Figure 1) were occupied and the maximum current electrode separation $(\mathrm{AB} / 2)$ utilized for the Schlumberger sounding was $125 \mathrm{~m}$. In groundwater and engineering studies for instance, the relevance of the method is based on the usually significant resistivity contrast between the weathered zone and or fractured

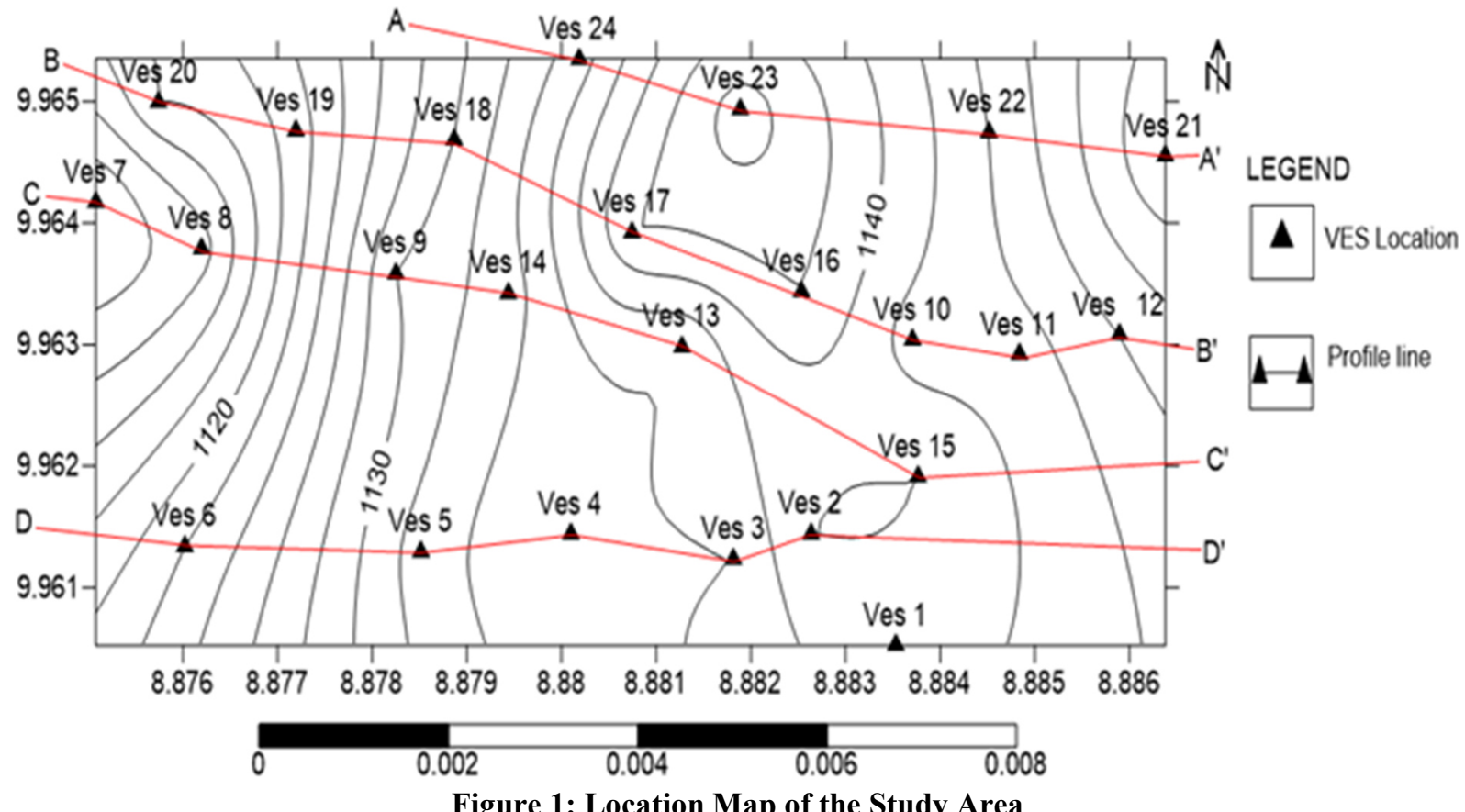

column (Olorunfemi and Fasuyi, 1993). The purpose of the vertical electrical sounding method is to investigate the change of the formation resistivity with depth. To achieve this purpose, it is necessary to arrange measurements in such a way that at different measurements, the value of the measured potential difference is affected by the formation resistivity at different depth ranges. This may be accomplished by changing the distance between the current electrodes so that the depth ranges to which the current penetrates is changed. However, the distance between the potential measuring electrodes and their position with respect to the current electrodes also affect the depth range from which information on the formation resistivity is obtained. In the configuration employed in this study (Schlumberger) the four electrodes are positioned on a straight line, with the two current electrodes on the outside of the potential measuring electrodes. The interpretation of the VES data is based on the assumption that the subsurface consists of a sequence of distinct layers of finite thickness and each of these layers is assured to be electrically homogeneous and isotropic (Koefoed,1979), and the boundary planes between subsequent layers are assumed to be horizontal.

The VES is based on the principle that a fraction of the electric current injected into the ground, penetrating below a given depth, increases with the separation of the current electrodes. Thus as the current electrode separation is increased, the depth of penetration will increase.

The field data was processed for easy interpretation by calculating apparent resistivity $\left(\rho_{\mathrm{a}}\right)$ value for each layer depth, which was done by multiplying the resistance by their respective geometric constants K, (i.e. $\rho_{\mathrm{a}}=\mathrm{R} \times$ $\mathrm{K})$. The processed data were interpreted using the computer Software called IPI2WIN where the field curves were compared with the computer-modelled curves to deduce the layer thickness (m), true resistivity values (' $\Omega \mathrm{m})$ for 
each layer and the percentage fitting error of each plot model.

\section{Results and Discussion}

\section{1: Sub-surface Lithology}

Information on the existing subsurface conditions on site is a critical requirement because it is useful in the planning and design stage of the building foundation and other underground works.

Three lithological geo-electric layers were delineated from the study area consisting of the top soil which is mostly lateritic, weathered/ fractured basement and the fresh basement as seen in Figures 2, 3, 4 and 5 respectively. The top lateritic soil thickness varies from 0.1-4.0 m; the weathered/ fractured basement has thickness that varies from 3.0 -25.0 m while that of the fresh basement ranges from $25.0 \mathrm{~m}$ - infinity. The resistivity values of these layers vary from $101 \Omega \mathrm{m}-821 \Omega \mathrm{m}$ for the top soil, $11.40 \Omega \mathrm{m}-99.98 \Omega \mathrm{m}$ for the weathered / fractured basement while that of the fresh basement ranges from $442 \Omega \mathrm{m}-5896.70 \Omega \mathrm{m}$ (Table 1) below. The VES points 13, 15, 19 and 24 have the thickest layers of weathered/ fractured basement while VES 4, 5, 6, 7, 8, 14 and 16 have shallower fresh basement thicknesses which implies that these areas are capable of anchoring heavy implied loads because of the high bearing capacity associated with fresh basement rocks.

Table 1: Resistivity Values, Thickness, Depth and Curve Types of VES Points in the Study Area

\begin{tabular}{|c|c|c|c|c|c|c|c|c|c|c|}
\hline $\begin{array}{l}\text { VES } \\
\text { Points }\end{array}$ & $\rho_{1}$ & $\rho 2$ & $\rho 3$ & $\rho 4$ & $\rho 5$ & $h_{1}$ & $h_{2}$ & $h_{3}$ & $h_{4}$ & $\begin{array}{l}\text { Curve } \\
\text { Type }\end{array}$ \\
\hline 1 & 379.23 & 51.44 & 1104.30 & 25.77 & & 2.8 & 12.6 & 16.5 & & $\mathrm{HK}$ \\
\hline 2 & 95.20 & 22.35 & 1421.60 & 13.41 & & 9.4 & 5.5 & 16.5 & & $\mathrm{HK}$ \\
\hline 3 & 547 & 80.49 & 34.34 & 212.48 & & 0.7 & 6.8 & 4.4 & & $\mathrm{QH}$ \\
\hline 4 & 527.69 & 119.30 & 200.24 & & & 1.1 & 15.8 & & & $\mathrm{H}$ \\
\hline 5 & 806.99 & 50.35 & 130.43 & & & 1.5 & 1.2 & & & $\mathrm{H}$ \\
\hline 6 & 394.46 & 101.87 & 25.40 & 187.98 & & 2.3 & 11.6 & 6.7 & & $\mathrm{QH}$ \\
\hline 7 & 688.75 & 134.56 & 456.01 & & & 1.6 & 3 & & & $\mathrm{QH}$ \\
\hline 8 & 6474.46 & 137.89 & 12.89 & 592.53 & & 0.5 & 8.0 & 6.5 & & $\mathrm{QH}$ \\
\hline 9 & 231.32 & 127.29 & 205.61 & 449.17 & & 1.3 & 1.1 & 22.4 & & HA \\
\hline 10 & 442.42 & 202.94 & 34.03 & 58957 & & 1.0 & 12.1 & 8.2 & & $\mathrm{QH}$ \\
\hline 11 & 203.66 & 53.24 & 14563 & & & 1.2 & 14.4 & & & $\mathrm{H}$ \\
\hline 12 & 389.80 & 88.90 & 1523.4 & 322.48 & & 2.3 & 7.1 & 11.6 & & $\mathrm{HA}$ \\
\hline 13 & 532.72 & 141.86 & 3247.7 & & & 1.8 & 42.7 & & & $\mathrm{H}$ \\
\hline 14 & 1060.9 & 424.17 & 26.29 & 2046.3 & & 1.4 & 2.9 & 5.6 & & $\mathrm{QH}$ \\
\hline 15 & 224.08 & 114.51 & 226.93 & 3063.8 & & 1.2 & 5.8 & 44.3 & & $\mathrm{HA}$ \\
\hline 16 & 821.19 & 223.61 & 19.10 & 3110.8 & 71.32 & 0.3 & 7 & 3.3 & 22.9 & QHK \\
\hline 17 & 395.07 & 114.31 & 616.07 & & & 0.3 & 24.6 & & & $\mathrm{H}$ \\
\hline 18 & 613.94 & 218.21 & 60.04 & 908.45 & & 1.1 & 7.9 & 10.6 & & $\mathrm{QH}$ \\
\hline 19 & 420.53 & 181.70 & 137.90 & 1264.9 & & 1.9 & 1.2 & 37.9 & & $\mathrm{QH}$ \\
\hline 20 & 490.63 & 104.34 & 11.4 & 1534.8 & & 1.0 & 5.5 & 5.1 & & $\mathrm{QH}$ \\
\hline 21 & 468.84 & 96.39 & 442.47 & & & 2.4 & 17.3 & & & $\mathrm{H}$ \\
\hline 22 & 101.20 & 19.33 & 7952.4 & & & 2.6 & 12.7 & & & $\mathrm{H}$ \\
\hline 23 & 6146.2 & 342.05 & 42.13 & 1235.2 & & 0.3 & 2.9 & 14.3 & & $\mathrm{QH}$ \\
\hline 24 & 461.28 & 24.27 & 99.98 & 2009.8 & & 2.1 & 1.4 & 39.1 & & $\mathrm{HA}$ \\
\hline
\end{tabular}




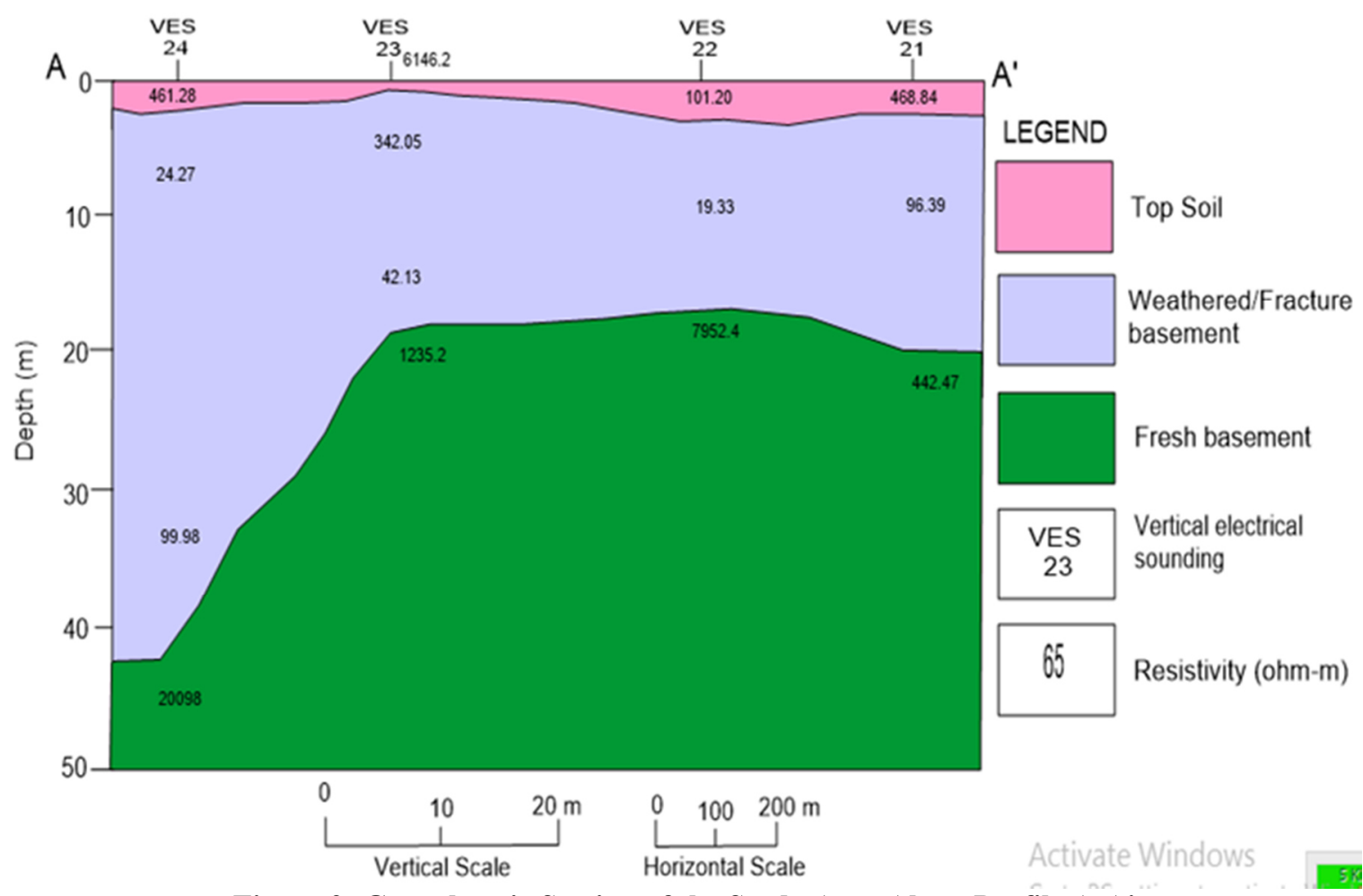

Figure 2: Geo- electric Section of the Study Area Along Profile A-A'

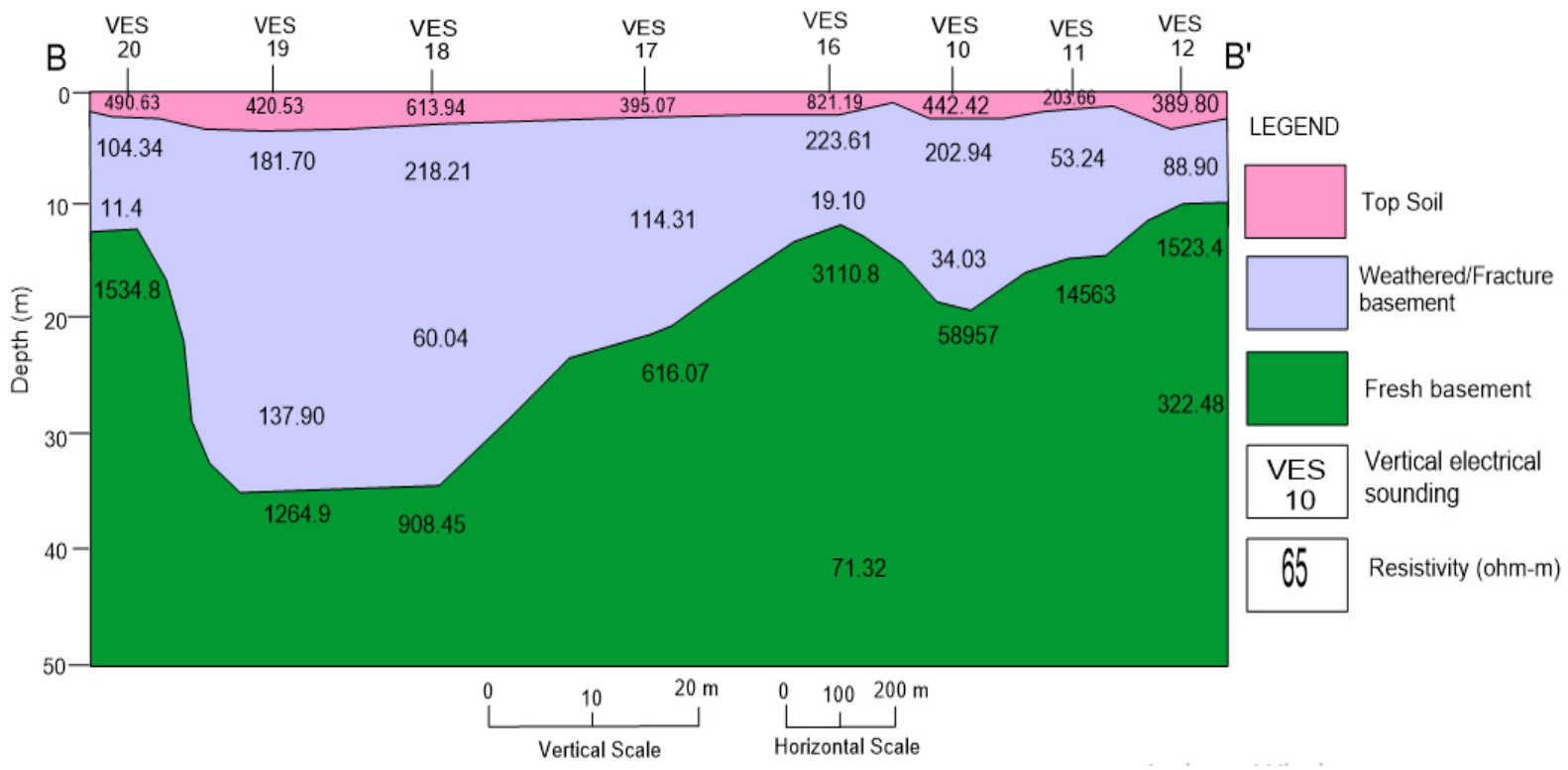

Figure 3: Geo- electric Section of the Study Area Along Profile B- B' 


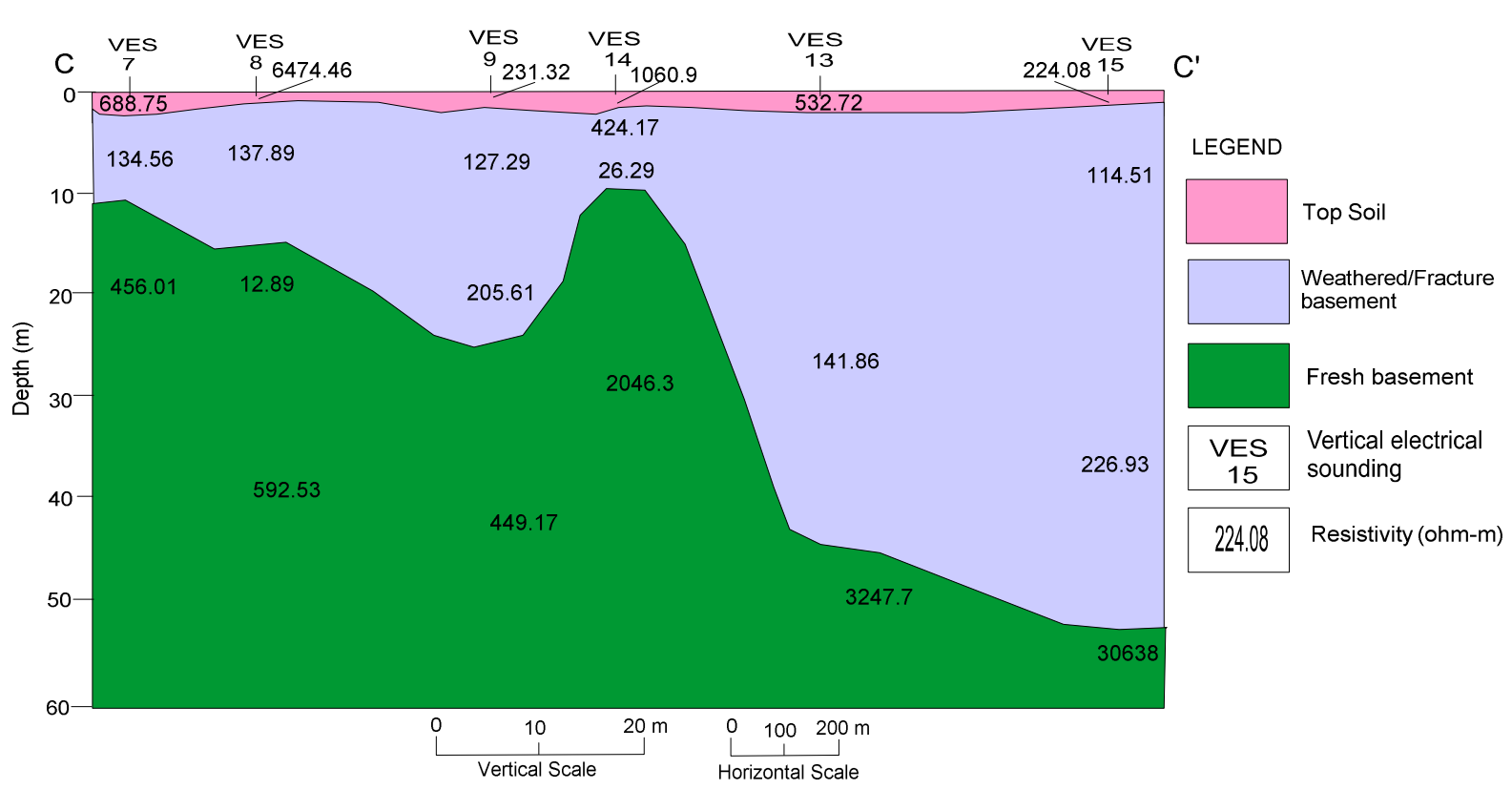

Figure 4: Geo- electric Section of the Study Area Along Profile C- $C^{\prime}$

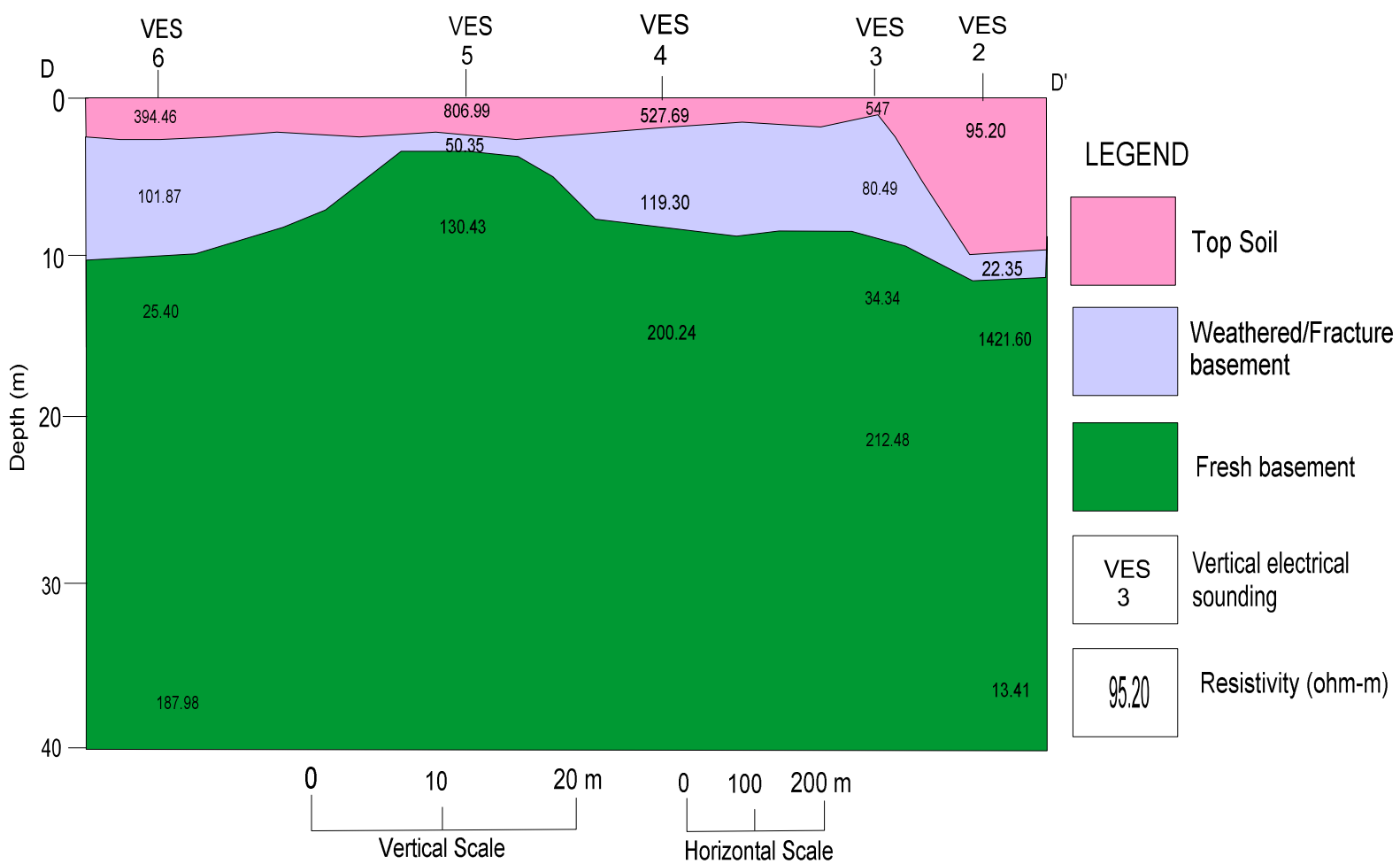

Figure 5: Geo- electric Section of the Study Area Along Profile D- D'

\section{2: Soil Competency}

The aim of any engineering site investigation whether through direct or indirect means is to determine the nature (competence) of the sub-surface strata that are capable of carrying the load that will be applied to it. Electrical resistivity values have been used by authors such as Sheriff (1991), Idornigie et al. (2006) and Bayowa and Olayiwola (2015) to classify earth materials into incompetent, moderately competent, competent and highly competent as shown in Table 2. Clay is characterized by low resistivity usually less than $100 \Omega \mathrm{m}$ are regarded as incompetent material as they tend to flow under stress whereas, sands and crystalline rocks are regarded as competent due to the fact that they can withstand stress because of the presence of sands mixed with clay. The sands in this zone would enhance the engineering capacity unlike the purely clayey horizon (Mosuro et al., 2012). Comparing the resistivity values in Table 1 with the standard as proposed by Bayowa and Olayiwola (2015) Table 2 , most of the layers are in the range of competent to highly competent. 
Table 2: Soil Competence Rating (After Bayowa and Olayiwola, 2015).

\begin{tabular}{|l|l|l|}
\hline Apparent Resistivity $\mathbf{( \Omega m})$ & Lithology & Competence Rating \\
\hline$<100$ & Clay & Incompetent \\
\hline $100-350$ & Sandy clay & Moderately Competent \\
\hline $350-750$ & Clayey sand & Competent \\
\hline$>750$ & Sand/Laterite/Bedrock & Highly Competent \\
\hline
\end{tabular}

\section{Conclusion}

Electrical resistivity method of geophysical prospecting has been used in geotechnical and engineering geology, groundwater exploration, contamination studies etc. The cost effectiveness of this method coupled with its suitability in determining the depth to bedrocks, types and thickness of sub- surface materials has made very convenient for use by Civil Engineers and Geotechnical/ Engineering Geologists to characterize the sub-surface before any meaningful construction can commence. Other advantages of the electrical resistivity method are that it saves time and it is environmentally-friendly because of its non-invasive nature. The data obtained in the course of the study identified three lithological units comprising of the top soil which are mostly lateritic, the weathered/ fractured basement and the fresh basement. The sub-surface layers range from competent to highly competent in view of the resistivity values measured. However, this can be complimented with borehole data to arrive at a more convincing conclusion.

\section{References}

Alastair, M., Paul, B., Eric, J., and Laurie, P. (2016). Geophysical Applications to construction Engineering Projects. Advisian (Worleyparsons Canada Services Ltd). Calgary, Alberta Canada

Clayton, C.R.I., Matthews, M.C. and Simons, N.E. (1996). Site Investigation. Second Edition. Blackwell Scientific Publishers, Oxford.

Idornigie, A.I., Olorunfemi, M.O. and Omitogun, A.A. (2006). Electrical Resistivity Determination of Surface Layers, Soil Competence and Soil Corrosivity at an Engineering Site Location in Akungba- Akoko, South Western Nigeria. Ife Journal of Science, 8(2).

Koefoed, O. (1979). Geosounding Principles 1: Resistivity Sounding Measurements. Elsevier Science Publishing Company, Amsterdam.

MacLeod, W.N., Turner, D.C., Wright, E. P. and Berridge, M.S. (1971). The Geology of the Jos Plateau. Geol. Surv. Nigeria, 32(1).

Moh'd, H.Z.A., Rosli, S., Fauziah, A., Devapriya, C.W. and Mohamad, F.T.B. (2011).

Application of Geophysical Methods in Civil Engineering. Malaysian Technical

Universities International conference on Engineering and Technology.

Mosuro, G.O., Oloruntola, M.O. Bayewu, O.O. (2012). Geophysical characterization of subsurface layers, soil competency and corrosivity at Igarran South West Nigeria. $5^{\text {th }}$ Saint Petersburg International conference and exhibition of Geosciences Russia, 3-6

Olorunfemi, M.O. and Fasuyi, S.A. (1993). Aquifer Types and the Geoelectric/ Hydrogeologic Characteristics of Part of Central Basement Terrain of Nigeria (Niger State). Journal of African Earth Sciences, 16, $309-317$.

Sheriff, R.E. (1991). Encyclopaedic Dictionary of Exploration Geophysics (3rd Ed.) Geophysical references series 1, Society of Exploration Geophysicists (SEG), Tulsa, Oklahoma, USA.

Soupios, P.M., Georgakopoulos, P., Papadopoulos, N., Saltas, V., Andreadakis, A., Vallianatos, F., Sarris, A. and Makris, J.P. (2007). Use of Engineering Geophysics to investigate a site for building foundation. Journal of Geophysics and Engineering 4(1) Pp 94-103 